Rev. Elet. em Gestão, Educação e Tecnologia Ambiental (e-ISSN: 2236-1170)

\title{
EVOLUÇÃO DA COBERTURA FLORESTAL NAS SERRAS DO SUDESTE, RIO GRANDE DO SUL, ENTRE 1984 E 2011
}

Juliana Marchesan, Diogo Belmonte Lippert, Rudiney Soares Pereira, Ana Caroline Paim Benedetti, Matheus Mesquita da Costa Nunes, Daiana Iris Brites

${ }^{1}$ juliana marchesan@hotmail.com

2 diogo b lippert@hotmail.com

3 rudiney.s.pereira@gmail.com

4 ac benedetti@yahoo.com.br

${ }^{5}$ matheusnunes florestal@hotmail.com

${ }^{6}$ daiana brites@hotmail.com

http://dx.doi.org/10.5902/223611706680

\section{RESUMO}

O objetivo do trabalho é avaliar mudanças no uso e cobertura da terra, sobretudo nas florestas, na microrregião Serras do Sudeste, Rio Grande do Sul nos anos de 1984, 1995, 2004 e 2011. Imagens do satélite Landsat 5 foram processadas no aplicativo SPRING para elaboração de um mapeamento temático, no qual foram definidas as seguintes classes de uso e cobertura da terra: "floresta nativa", "floresta plantada", "campo", "solo exposto" e "água". Observou-se um acréscimo na área de florestas plantadas, em consequência ocorre também um aumento gradativo da vegetação nativa, isso pode ser explicado pela forma com que a silvicultura vem sendo praticada nos últimos anos, respeitando áreas de preservação permanente (APP) e criando áreas de reserva legal.

Palavras chave: uso e cobertura da terra; sensoriamento remoto; SIG; classificação digital.

\section{ABSTRACT}

The objective is to evaluate changes in land use and land cover, especially forests, microregion Serras do Sudeste, Rio Grande do Sul, in 1984, 1995, 2004 and 2011. Landsat 5 satellite images were processed by SPRING to develop thematic maps, defined the following classes of land use and land cover: "native forest", "planted forest", "field", "soil" and "water". We observed an increase in the area planted forests, as a result there is a gradual increase of native vegetation, this can be explained by the way forestry has been practiced in recent years, respecting permanent preservation areas (APP) and creating reserve areas.

Key words: land use and land cover; remote sensing; GIS; digital classification.

\section{INTRODUÇÃO}

Ao longo do tempo, a cobertura florestal nativa presente nos diferentes biomas foi sendo fragmentada, cedendo espaço para as culturas agrícolas, pastagens e para a expansão urbana (MARTINS, 2001). A microrregião Serras do Sudeste está inserida no Bioma Pampa, sendo que esse 
Rev. Elet. em Gestão, Educação e Tecnologia Ambiental (e-ISSN: 2236-1170)

abrange 63\% do território do Rio Grande do Sul (IBGE, 2012). Segundo Benedetti (2010), a pecuária era considerada a "base econômica" dos municípios localizados nessa região e há tempos vem reduzindo sua taxa de expansão e freando o crescimento regional, soma-se a isso, a falta de empreendedorismo e inovação tecnológica.

Gracioli (2010) relata que a Serras do Sudeste, em particular, constitui um espaço geográfico onde o desenvolvimento econômico tem sido, até então, baseado na atividade de pecuária, mostrando-se, atualmente, como promissora em relação à diversificação de atividades. Dados da Fundação de Economia e Estatística (FEE, 2009), mostram que desde o ano de 1939, a Metade Sul passou a ter uma participação inferior no produto interno bruto (PIB) do Estado.

Parte desse fato decorre do conservadorismo dos proprietários de terras, que não têm por hábito diversificar sua produção, seja pela inadequação do solo para alguns cultivos, seja pela distância aos centros consumidores e de pouca inter-relação comercial, concentração de renda nas mãos de poucos e mesmo pela insuficiência da rede viária (CORONEL et al., 2007).

No ano de 2003, foi lançado pelo governo do Rio Grande do Sul o Programa Estadual de Florestamento que, dentre outros objetivos, previa fomentar o florestamento comercial em municípios da Metade Sul através da implantação de 40 mil hectares de maciços florestais, podendo gerar, até 2014, uma receita bruta de $\mathrm{R} \$ 200$ milhões aos produtores (BENEDETTI, 2010; SANTOS et al., 2007). Desde esse período, a Metade Sul tem sido foco de investimentos por parte de empresas multinacionais do setor de celulose e papel e de laminados, as quais poderão tornar a região um polo para o suprimento de demandas do setor papeleiro e madeireiro.

Através das técnicas de Sensoriamento Remoto e Sistemas de Informação Geográfica (SIG) é possível realizar o monitoramento do uso e cobertura da terra de forma prática e obter informações para avaliar a dinâmica da paisagem (NOVO, 2008). A expressão "uso da terra" pode ser entendida como a forma pela qual o espaço está sendo ocupado pelo homem (ROSA, 1992), sendo assim, é importante considerar se o mesmo é explorado de forma organizada e produtiva. Autores como Briassoulis (1999) e Turner et al., (1994) definem o termo "cobertura da terra" como sendo a caracterização dos estados físico, químico e biológico da superfície terrestre, como por exemplo, floresta, gramíneas, água, ou área construída; já, o termo "uso da terra" refere-se aos propósitos humanos associados àquela determinada cobertura, por exemplo, pecuária, recreação, conservação, área residencial.

O trabalho tem por objetivo avaliar a dinâmica do uso da terra ocorrida entre os anos de 1984, 1995, 2004 e 2011 na área pertencente a microrregião da Serra do Sudeste, Rio Grande do Sul.

\section{MATERIAL E MÉTODOS}

\section{Localização e caracterização da área de estudo}

A microrregião Serras do Sudeste pertencente à Metade Sul do Rio Grande do Sul e está localizada entre as coordenadas geográficas 3011'35" e 3206'13" de latitude sul e 51이'15" e 54ำ12'26" de longitude oeste, abrangendo uma área total de 16.522,81 Km² (IBGE, 2012). É composta pelos seguintes municípios: Amaral Ferrador, Caçapava do Sul, Candiota, Encruzilhada do Sul, Pedras Altas, Pinheiro Machado, Piratini e Santana da Boa Vista.

É entremeada de vegetação arbórea e herbácea em grandes extensões, surgem ainda formações únicas nessas paisagens (BOLDRINI, 2010; GRACIOLI, 2010). Com relação ao relevo, 
Rev. Elet. em Gestão, Educação e Tecnologia Ambiental (e-ISSN: 2236-1170)

destacam-se os afloramentos rochosos nas encostas e nos altos platôs, o solo muitas vezes é quase inexistente, a frequência de arbustos de diversas espécies resulta em paisagens que variam desde os "campos sujos" até as formações arbustivas compactas (RAMBO, 1942).

De acordo com a classificação de Köeppen, o clima é subtropical úmido (Cfa), com temperaturas que variam entre 14 으 e $18^{\circ} \mathrm{C}$. As precipitações são distribuídas durante 0 ano, apresentando variações anuais entre $1.300 \mathrm{~mm}$ e $1.500 \mathrm{~mm}$ (MORENO, 1961).

\section{Material}

Foi utilizado o aplicativo SPRING (Sistema de Processamento de Informações Georreferenciadas) versão 5.1.8. As imagens utilizadas (Tabela 1) foram do satélite LANDSAT 5, sensor Thematic Mapper (TM), com resolução espacial de 30 metros, disponibilizadas gratuitamente pelo Instituto Nacional de Pesquisas Espaciais (INPE, 2012).

Tabela 1 - Relação das cenas Landsat $5 e$ as respectivas datas avaliadas.

\begin{tabular}{r|cccccc}
\hline \multicolumn{1}{c|}{ Cena } & Órbita & Ponto & $\mathbf{1 9 8 4}$ & $\mathbf{1 9 9 5}$ & $\mathbf{2 0 0 4}$ & $\mathbf{2 0 1 1}$ \\
\hline $\mathbf{1}$ & 221 & 081 & $01 / 10$ & $01 / 11$ & $08 / 10$ & $28 / 10$ \\
$\mathbf{2}$ & 222 & 081 & $11 / 12$ & $23 / 10$ & $15 / 10$ & $04 / 11$ \\
$\mathbf{3}$ & 222 & 082 & $11 / 12$ & $23 / 10$ & $02 / 12$ & $04 / 11$ \\
\hline
\end{tabular}

\section{METODOLOGIA}

Primeiramente adquiriram-se as imagens em formato Geotiff, sendo necessárias três cenas para o recobrimento total da área de estudo. Posteriormente, para a importação das imagens, foi criado um banco de dados espaciais no SPRING, onde se criou um projeto para definir a projeção geográfica, o sistema de referência e para delimitar área de estudo através de um retângulo envolvente contendo suas coordenadas.

Após a realização desses procedimentos, foram importadas as imagens e também o arquivo vetorial correspondente ao polígono limite da área de estudo, o qual foi utilizado para recortar a área de interesse. Para identificação dos alvos, optou-se pela composição de imagens falsa-cor RGB (Red, Green e Blue) contendo as bandas espectrais 5, 4 e 3 do sensor TM. A técnica de contraste linear foi utilizada para melhor visualização dos diferentes padrões de uso e cobertura encontrados nas imagens, nas diferentes datas.

Foi realizada a classificação supervisionada das imagens, técnica que consiste em classificar pixel a pixel, criando um conjunto de características espectrais de cada uma das classes de uso e cobertura da terra, onde é associado determinado pixel da imagem a uma das classes contidas no pacote de treinamento, considerando um pixel como uma entidade isolada e independente dos pixels que compõem o restante da cena (MOREIRA, 2007). Para esse procedimento foi utilizado o algoritmo MaxVer (Máxima Verossimilhança).

Para o mapeamento temático foram adotadas as seguintes classes: "floresta nativa", "floresta plantada", "campo" (incluem pastagem, campo sujo e vegetação rasteira), "solo exposto" 
Rev. Elet. em Gestão, Educação e Tecnologia Ambiental (e-ISSN: 2236-1170)

(incluem área agrícolas em preparação ou em pousio) e "água" (incluem rios, arroios, banhados e açudes).

Para avaliar a qualidade da classificação, foi utilizada a tabela proposta por Landis e Koch (1977), contendo uma escala de valores, os quais definem a qualidade da classificação segundo o coeficiente Kappa (Tabela 2). Congalton e Green (1999) descrevem que o coeficiente é baseado na diferença entre a concordância observada (diagonal principal da matriz de confusão com a concordância entre a classificação e os dados de referência) e a chance de concordância entre os dados de referência e uma classificação aleatória (produto entre as totais marginais da matriz de classificação).

Tabela 2 - Qualidade da classificação segundo intervalos do coeficiente Kappa.

\begin{tabular}{c|c}
\hline Valor Kappa & Qualidade da classificação \\
\hline$<0,00$ & Péssima \\
\hline $0,00-0,20$ & Ruim \\
\hline $0,20-0,40$ & Razoável \\
\hline $0,40-0,60$ & Boa \\
\hline $0,60-0,80$ & Muito Boa \\
\hline $0,80-1,00$ & Excelente \\
\hline
\end{tabular}

Fonte: Landis e Koch (1977).

\section{RESULTADOS E DISCUSSÕES}

Os mapas de uso e cobertura da terra (Figuras 1, 2, 3 e 4) foram obtidos pela classificação digital das imagens dos anos de 1984, 1995, 2004 e 2011 respectivamente. Para esses mapas, obtiveram-se os seguintes valores do coeficiente Kappa para as amostras obtidas durante a fase de "treinamento" da classificação digital: 0,995 (99,5\%); 0,962 (96,2\%); 0,959 (95,9\%); 0,995 (99,5\%), qualificando os resultados como excelentes, de acordo com a Tabela 2. A quantificação das classes (Tabela 3) demonstra suas taxas de expansão e redução percentual ao longo do período de análise, igualmente observadas na Figura 5.

Tabela 3 - Quantificação das classes temáticas da microrregião Serras de Sudeste, RS, nos anos de 1984, 1995, 2004 e 2011.

\begin{tabular}{ccccc}
\hline \multirow{2}{*}{ Classe temática } & \multicolumn{4}{c}{ Área (ha) } \\
\cline { 2 - 5 } & $\mathbf{1 9 8 4}$ & $\mathbf{1 9 9 5}$ & $\mathbf{2 0 0 4}$ & $\mathbf{2 0 1 1}$ \\
\hline Floresta nativa & $189.475,94$ & $259.135,09$ & $267.557,98$ & $459.597,10$ \\
Floresta plantada & $19.418,45$ & $60.264,39$ & $60.253,48$ & $182.453,25$ \\
Campo & $1.243 .152,72$ & $966.725,41$ & $881.800,93$ & $726.421,50$ \\
Solo exposto & $196.095,70$ & $363.053,36$ & $438.309,97$ & $277.670,04$ \\
Água & $4.138,44$ & $3.103,00$ & $4.358,86$ & $6.141,36$ \\
\hline Total & $1.652 .281,25$ & $1.652 .281,25$ & $1.652 .281,25$ & $1.652 .281,25$ \\
\hline
\end{tabular}

Observa-se um significativo acréscimo de áreas de florestas nativas, apresentando um desenvolvimento exponencial durante o intervalo de tempo avaliado. Sua expansão, em 2011, é 
Rev. Elet. em Gestão, Educação e Tecnologia Ambiental (e-ISSN: 2236-1170)

quantificada em 270.121,16ha em relação à primeira data de análise (1984). Esse aumento, segundo Lippert et al., (2012) também ocorreu na região noroeste do estado, e pode estar relacionado com a legislação, com o aumento na fiscalização e punição aos crimes ambientais, ocasionando com isso uma maior preservação e assim criando condições para a regeneração de vegetação nativa.

As áreas de florestas plantadas com gêneros exóticos, como Eucalyptus, Pinus e Acacia, também apresentaram um aumento considerável, contabilizado em $163.034,16$ ha ao fim do período. Esses florestamentos ocorrem, em sua maioria, por meio de empresas do setor de celulose e papel. Destaca-se ainda, a ocorrência de sistemas agrossilvipastoris, que constituem uma alternativa de renda aos pecuaristas, dessa forma, contribuindo para o aumento da atividade silvicultural na microrregião.

Os campos são predominantes em todas as datas avaliadas, porém constata-se um decréscimo constante em suas áreas. Ao fim do período foram reduzidos em 516.731,22ha. Essa redução é, em parte, ocasionadapela expansão florestal (nativa e plantada), uma vez que essas são estabelecidas principalmente em áreas de campo, ocupadas anteriormente para a prática da pecuária extensiva. Outro fator atribuído aessa retração é a conversão para solo exposto, devido sua utilização para a agricultura. O uso inadequado do campo, com uma superlotação de animais, também pode ter contribuído, prejudicando o desenvolvimento de gramíneas formadoras de campos.

As áreas de solo exposto apresentaram um aumento gradativo até o ano de 2004, porém 2011 foram reduzidas, e se comparadas com o primeiro ano (1984), seu acréscimo é quantificado em $81.574,34$ ha. Com a expansão das culturas agrícolas, para regiões que no passado eram predominantemente ocupadas pela pecuária de corte, pode se perceber que ocorre a substituição do campo pela agricultura de verão, e essas áreas no inverno ficavam descobertas por vegetação; com passar dos anos, pode ser percebido que em 2011, essas passam a receber coberturas de inverno.

As lâminas d'água não apresentamuma dinâmica tão expressiva quanto às demais classes. Denota-se um acréscimo de 2.002,92ha no ano de 2011 em relação a 2004. Um fator relevante para esse aumento seria uma maior preocupação no armazenamento da água captada das chuvas, devido à ocorrência de grandes estiagens nos últimos anos e também uma maior fiscalização dos órgãos competentes na origem da água utilizada para abastecer as lavouras, nesse caso as de arroz. 
Rev. Elet. em Gestão, Educação e Tecnologia Ambiental (e-ISSN: 2236-1170)

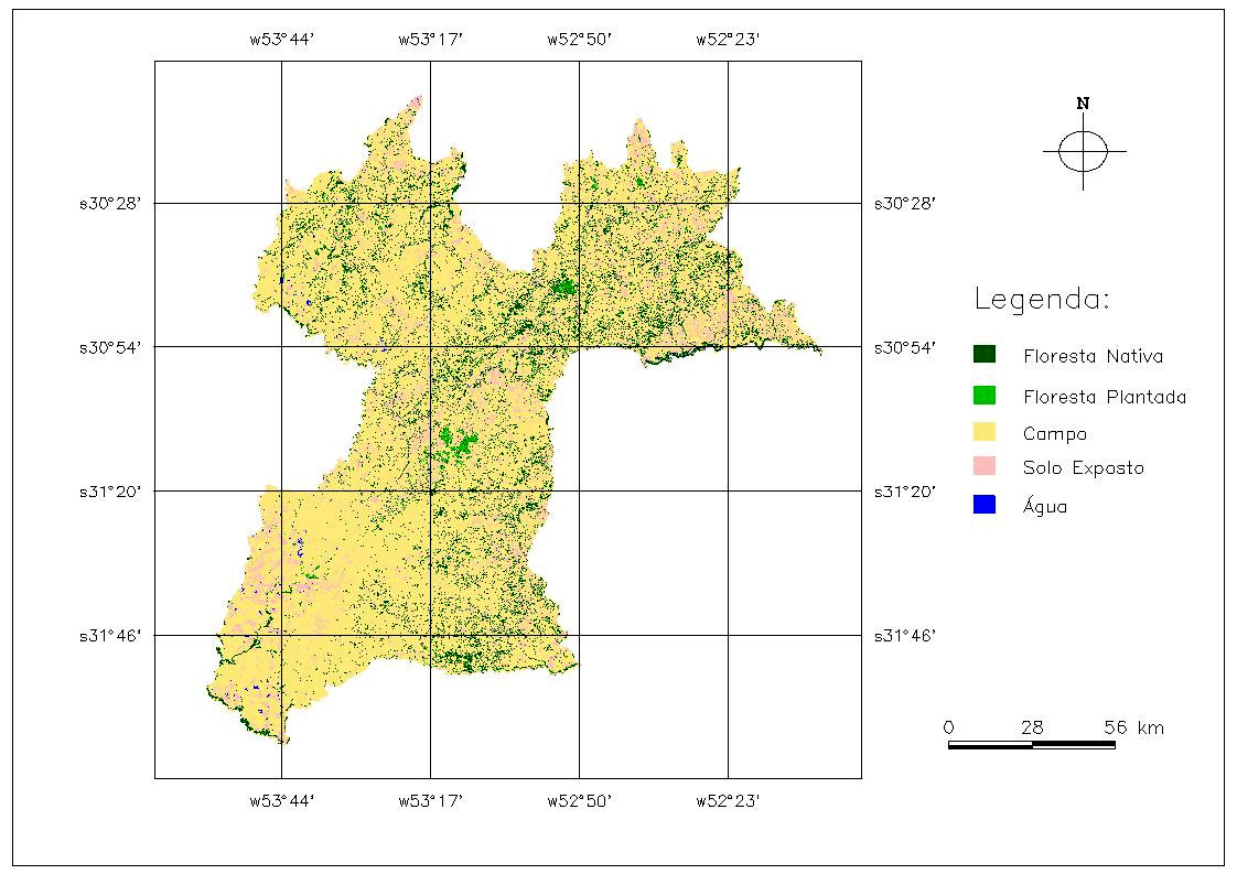

Figura 1: Mapa de uso e cobertura da terra em 1984 na microrregião Serras do Sudeste, RS.

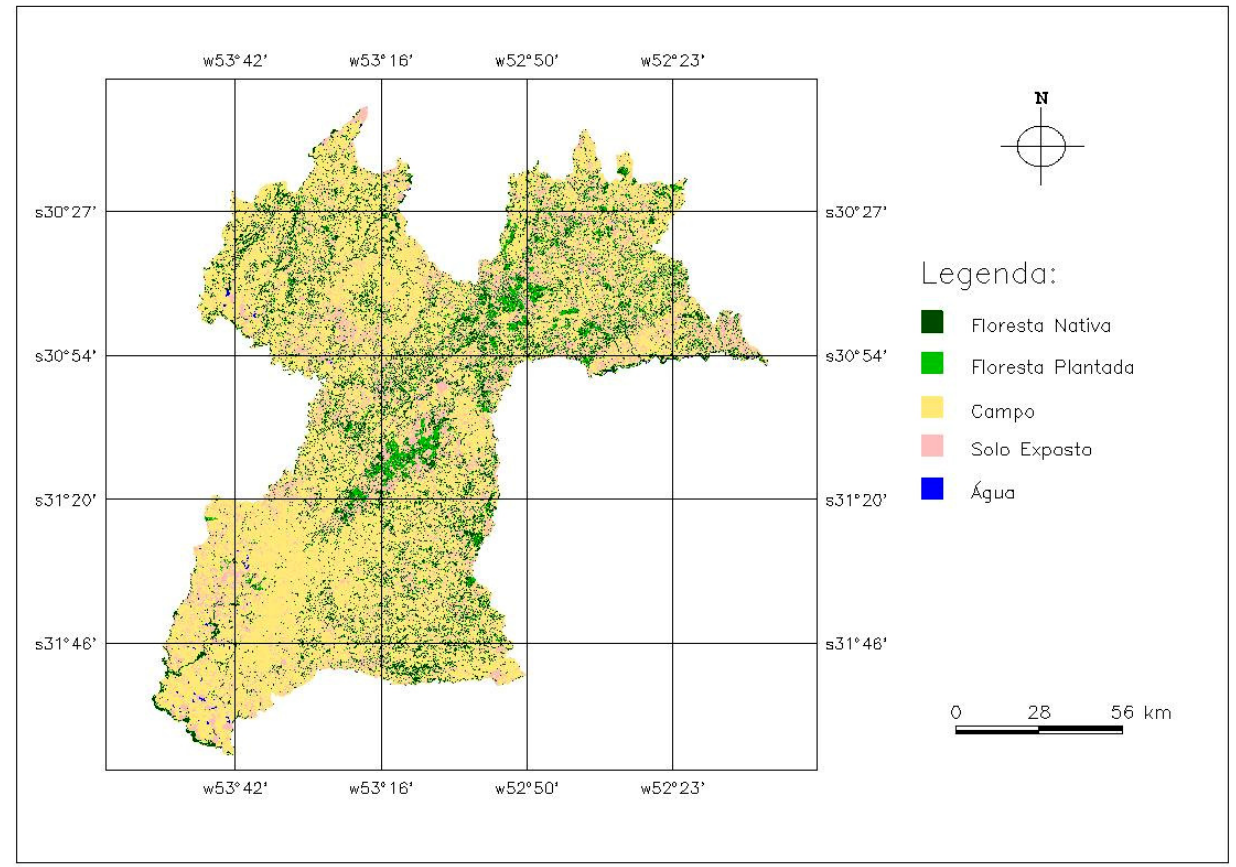

Figura 2: Mapa de uso e cobertura da terra em 1995 na microrregião Serras do Sudeste, RS. 
Rev. Elet. em Gestão, Educação e Tecnologia Ambiental (e-ISSN: 2236-1170)

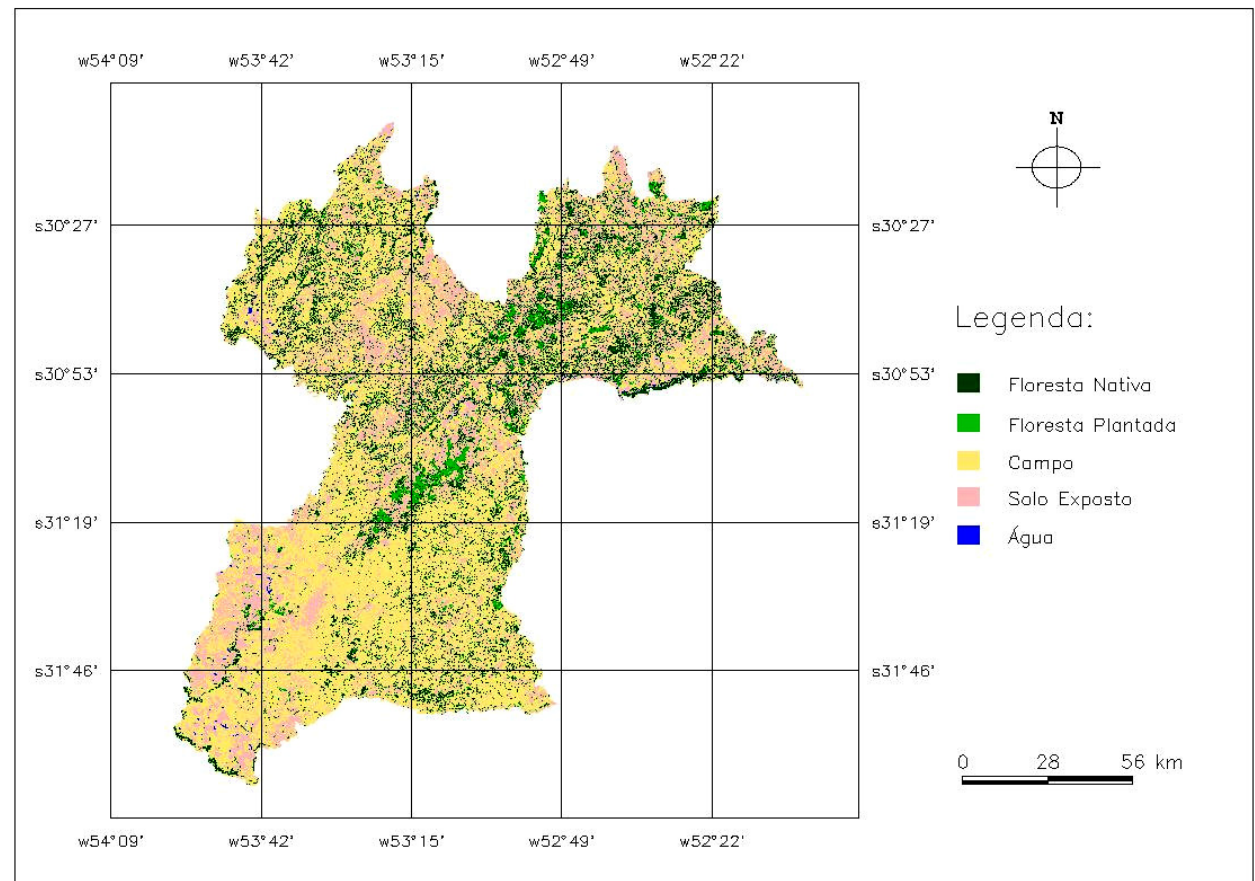

Figura 3: Mapa de uso e cobertura da terra em 2004 na microrregião Serras do Sudeste, RS.

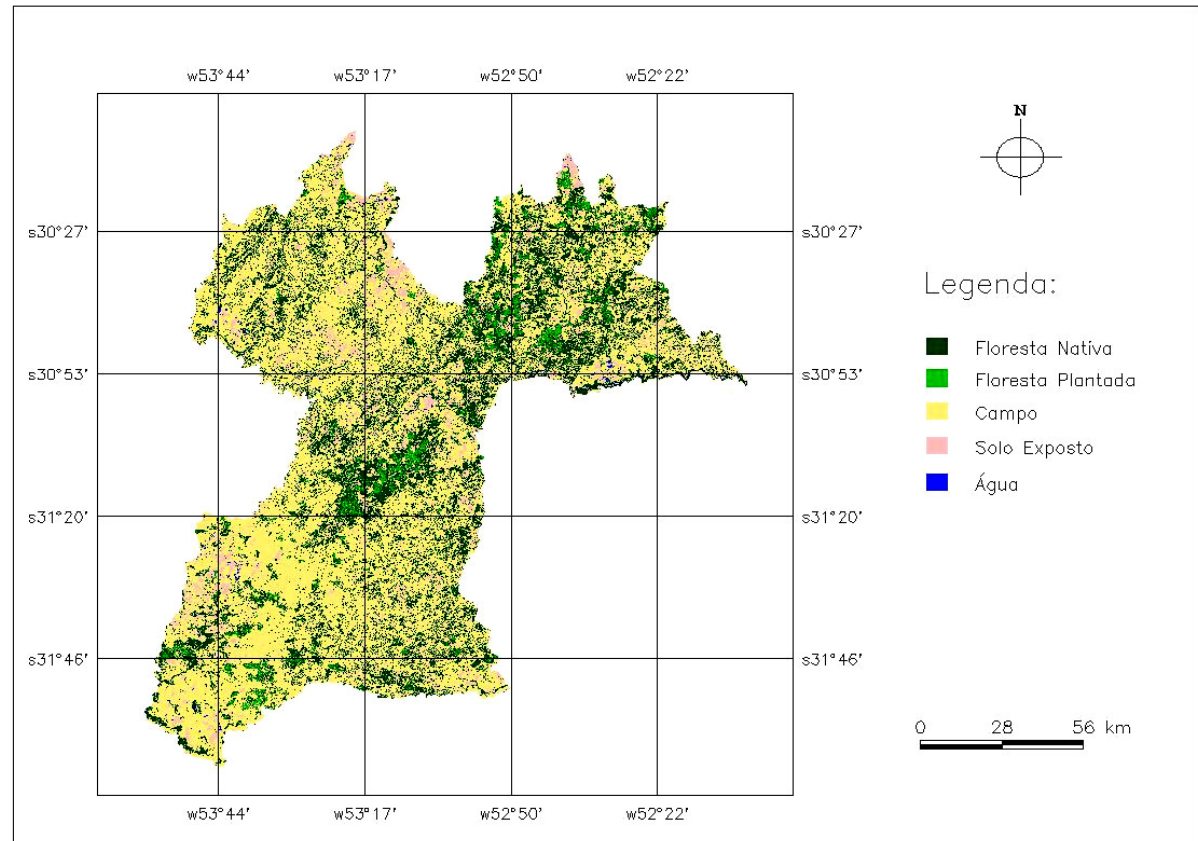

Figura 4: Mapa de uso e cobertura da terra em 2011 na microrregião Serras do Sudeste, RS. 
Rev. Elet. em Gestão, Educação e Tecnologia Ambiental (e-ISSN: 2236-1170)

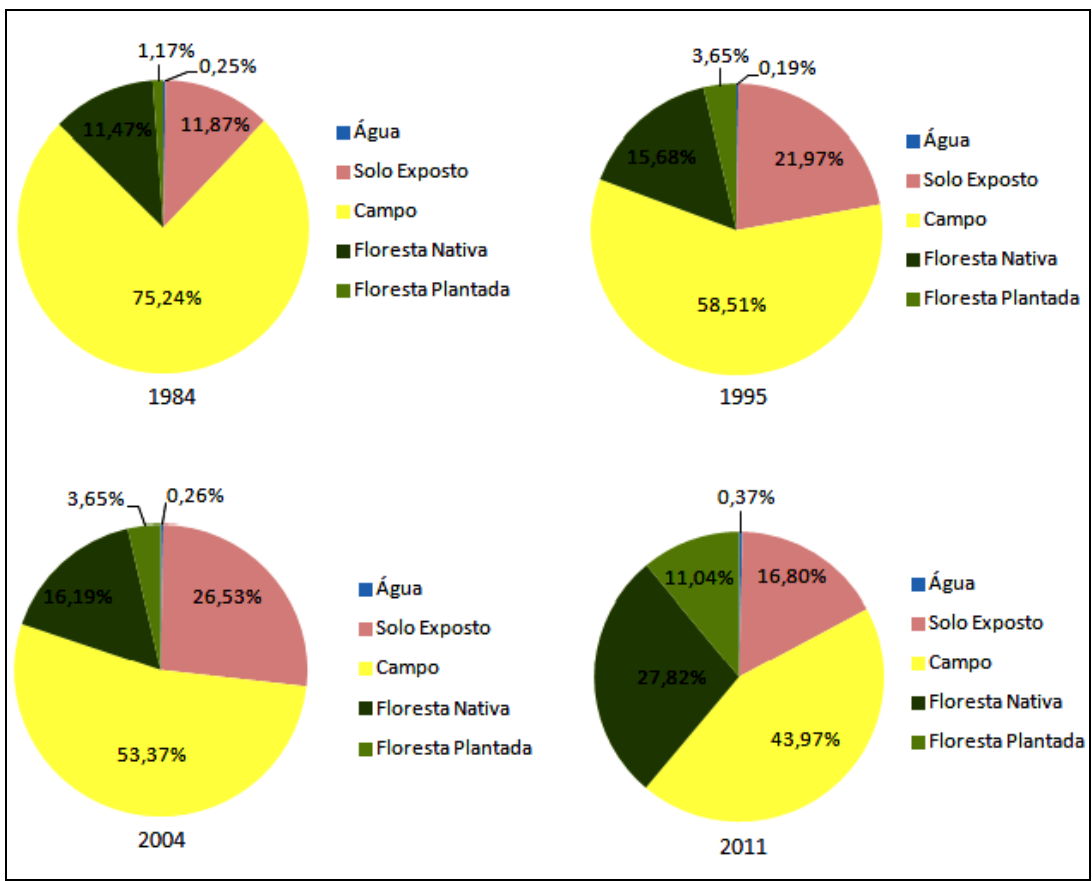

Figura 5: Evolução das classes temáticas na microrregião Serras de Sudeste, respectivamente dos anos de 1984, 1995, 2004 e 2011.

\section{CONCLUSÃO}

As imagens do sensor TM do satélite Landsat 5, mostraram-se eficientes para observações do uso e cobertura da terra na microrregião estudada, permitindo assim verificar as principais mudanças ocorridas na paisagem em um período de vinte e sete anos. Os mapas temáticos gerados permitiram avaliar a evolução da cobertura florestal (floresta plantada e floresta nativa), do campo, do solo exposto e da água, além de quantificar a área respectiva em cada ano.

Pode-se constatar que houve um aumento na área de floresta plantada, em consequência ocorre também um aumento gradativo da vegetação nativa, isso pode ser explicado pela forma com que a silvicultura vem se realizando nos últimos anos, respeitando áreas de preservação permanente (APP) e criando áreas de reserva legal. Por outro lado, o que também pode ocorrer é crescimento de vegetação nativa em áreas anteriormente ocupadas pela agricultura e pecuária, as quais podem ser decorridas pelo êxodo rural.

\section{REFERÊNCIAS BIBLIOGRÁFICAS}

BENEDETTI, A. C. P. Modelagem dinâmica para simulação de mudanças na cobertura florestal das Serras do Sudeste e Campanha Meridional do Rio Grande do Sul. 2010. 166 f. Tese (Doutorado em Engenharia Florestal) - Universidade Federal de Santa Maria, Santa Maria, 2010.

BOLDRINI, I. I.; FERREIRA, P. M. A.; ANDRADE, B. O.; SCHNEIDER, A. A.; SETUBAL, R. B.; TREVISAN, R; FREITAS, E. M. Bioma Pampa: diversidade florística e fisionômica. Porto Alegre: Pallotti, 2010. 
BRIASSOULIS, H. Analysis of Land Use Change: Theoretical and Modeling Approaches. In: Regional Research Institute. West Virginia University, 1999. Disponível em: <http://www.rri.wvu.edu/WebBook/Briassoulis/contents.htm>. Acesso em 12 mar. 2012.

CONGALTON, R. G.; GREEN, K. Assessing the accuracy of remotely sensed data: principles and practices. New York: Lewis Publishers, 1999.

CORONEL, D. A.; ALVES, F. A.; SILVA, M. A. Notas sobre o processo de desenvolvimento da Metade Sul e Norte do Estado do Rio Grande do Sul: uma abordagem comparativa. Perspectiva Econômica. São Leopoldo, vol. 3, n. 2, jul - dez. 2007.

FEE. FUNDAÇÃO DE ECONOMIA E ESTATÍSTICA. Disponível em: http://www.fee.tche.br/sitefee/pt/content/capa/index.php. Acesso em 08 jul. 2009.

GRACIOLI, C. R. Efeitos da silvicultura do eucalipto na dinâmica da vegetação em área de pecuária no Rio Grande do Sul, Brasil. 2010. 143 f. Tese (Doutorado em Engenharia Florestal) Universidade Federal de Santa Maria, Santa Maria, 2010.

IBGE - Instituto Brasileiro de Geografia e Estatística. Disponível em: <http://www.ibge.gov.br>. Acesso em 17 ago. 2012

INPE - Instituto Nacional de Pesquisas Espaciais. Disponível em: <http://www.inpe.br>.Acesso em: 10 ago. 2012.

LANDIS, J.; KOCH, G. G.The measurements of agreement for categorical data. Biometrics, Washington, v. 33, n. 3, p. 159-179, Mar. 1977.

LIPPERT, D. B. et al. Dinâmica da cobertura florestal no município de Crissiumal-RS, durante um período de vinte anos. Rev. Elet. em Gestão, Educação e Tecnologia Ambiental, v.7, n. 7, p. 12971305, 2012.

MARTINS, S. V. Recuperação de Mata Ciliar. Viçosa: Aprenda Fácil, 2001.

MOREIRA, M. A. Fundamentos do Sensoriamento Remoto e metodologias de aplicação. 3. ed. rev. e ampl. 1. reimpressão Viçosa: UFV, 2007.

MORENO, J. A. Clima do Rio Grande do Sul. Porto Alegre: Secretaria da Agricultura. 1961.

NOVO, E. M. L. de Moraes. Sensoriamento Remoto: princípios e aplicações. São Paulo, SP: Editora Blucher, 2008.

RAMBO, B. A fisionomia do Rio Grande do Sul: ensaio de monografia natural. Porto Alegre: Imprensa Oficial, 1942. 
ROSA, R. Introdução ao Sensoriamento Remoto. 2a ed.rev. Uberlândia. Ed. Da Universidade Federal de Uberlândia, 1992.

SANTOS, O. I. B. et al. Perspectivas de desenvolvimento sustentável da Metade Sul do Rio Grande do Sul com base nos arranjos silvícolas emergentes e na produção de etanol a partir de celulose. In: Encontro Nacional sobre Gestão Empresarial e Meio Ambiente, 9, 2007, Curitiba. Anais... Curitiba: ENGEMA, 2007. p. 1-17.

TURNER, B.L.; MEYER, W. B.; SKOLE, D. Global land-use/land cover change: Towards an integrate study. Ambio, v.23, n.1, p. 91-95, 1994. 